\title{
An optics and photonics exhibit that reunites, educates and, engages: a meeting with light
}

Jean-Christophe Gauthier, Madison Rilling, Guillaume Allain, Frédéric Jobin, Alex Côté, et al.

Jean-Christophe Gauthier, Madison Rilling, Guillaume Allain, Frédéric Jobin, Alex Côté, Xavier Dallaire, Simon Duval, Clément Frayssinous, Samuel Gouin, Sébastien Magnan, Vincent Michaud-Belleau, "An optics and photonics exhibit that reunites, educates and, engages: a meeting with light," Proc. SPIE 10741, Optics Education and Outreach V, 107410A (14 September 2018); doi: 10.1117/12.2319990

SPIE Event: SPIE Optical Engineering + Applications, 2018, San Diego, California, United States 


\title{
An optics \& photonics exhibit that reunites, educates and engages: A Meeting with Light
}

\author{
Jean-Christophe Gauthier ${ }^{1,2}$, Madison Rilling ${ }^{1,2}$, Guillaume Allain ${ }^{1,2}$, Frédéric Jobin ${ }^{1,2}$, Alex \\ Côté $^{1,2}$, Xavier Dallaire ${ }^{1,2}$, Simon Duval ${ }^{1,2}$, Clément Frayssinous ${ }^{1,2}$, Samuel Gouin ${ }^{1,2}$, Sébastien \\ Magnan $^{1,2}$, and Vincent Michaud-Belleau ${ }^{1,3}$ \\ ${ }^{1}$ Centre d'optique, photonique et laser, Québec, QC, Canada \\ ${ }^{2}$ Départment de physique, de génie physique et d'optique, Université Laval, Québec, QC, \\ Canada \\ ${ }^{3}$ Départment de génie électrique et de génie informatique, Université Laval, Québec, QC, \\ Canada
}

\begin{abstract}
During the 2015 International Year of Light, Université Laval's SPIE Student Chapter volunteered to create a fully autonomous exhibition explaining the basics of light to the public. Composed of two informative banners and four modules each displaying a live experiment related to both fundamental and technological aspects of light, the goal of the exhibit A Meeting with Light was to illustrate the importance of light-based technologies and their role in our daily lives. Following its debut on campus, the exhibit traveled to several public libraries and major events such as Photonics North, IONS Québec and career fairs. Originating from student initiative and dedicated volunteer work from the Student Chapter, the project was made financially viable through a close collaboration with SPIE, The Optical Society (OSA) and partnerships with local optics-related companies.

Now more than two years after its first exposition and since meeting over 2000 people, it is possible to evaluate the factors that contributed to the success of the exhibit and of its continued use. A Meeting with Light is a great example of an outreach project that successfully reached its goal of promoting optics and photonics to a broader audience. In doing so, it brought together local leaders from academia, industry and government. We will discuss lessons learned by the Student Chapter in developing such a project, and we will hint at how it influenced our next major outreach project for the first International Day of Light in May 2018.
\end{abstract}

Keywords: Science Outreach, Science Exhibit, Education and Training in Optics and Photonics, Student Chapter, Student Initiative, International Year of Light, International Day of Light

\section{INTRODUCTION}

With over 40 companies related to the field of Optics and Photonics (O\&P), Québec City (Québec, Canada) is home to many of North America's major players in light-related technologies. Despite generating more than 3000 jobs and over $\$ 400 \mathrm{M}$ in total revenues ${ }^{12}$, on top of producing world-class academic research, the O\&P community remains quite unknown to the city's population. For this reason, Université Laval's SPIE Student Chapter (Regroupement des étudiants en photonique et optique de Laval - REPOL) has made a point of providing visibility to the field of $\mathrm{O} \& \mathrm{P}$ for at least 10 years now. Every year, the REPOL organizes a number of outreach activities, mostly aimed at local elementary and high school students. However, the 2015 International Year of Light (IYL) proved to be an excellent opportunity for reaching out to the general public by means of a larger and more ambitious project. Taking advantage of our chapter's outreach experience and reputation gained throughout the years, the REPOL's 2015 executive committee created a public and autonomous museum-like exhibit called A Meeting with Light (Rencontre avec la lumière in French). The exhibit toured the city by being exposed in public libraries and various large-scale events. This allowed people of different ages and backgrounds to discover basic principles of light and learn about both the academic and industrial O\&P community. This

Further author information: (Send correspondence to Madison Rilling)

Madison Rilling: E-mail: madison.rilling.1@ulaval.ca

Optics Education and Outreach V, edited by G. Groot Gregory, Proc. of SPIE Vol. 10741, 107410A

(c) 2018 SPIE · CCC code: $0277-786 X / 18 / \$ 18 \cdot$ doi: $10.1117 / 12.2319990$ 
project was made possible through partnerships with several companies and public organizations, and is a perfect example of the significant impact that a small group of dedicated graduate students can have within their city and how they succeeded in bringing together important members of industry, academia and government as they brought science and society together.

In order to share our experience in bringing to life A Meeting with Light and the potential impact of such projects with fellow student chapters, we will discuss the organization and creation process of the exhibit, while highlighting the various challenges encountered along the way. We will also present the estimated impact of the project on the public and on the O\&P community, and share the lessons learned by our Student Chapter in carrying out this project. Finally, stemming from this rich experience, we will introduce our most recent large-scale outreach project called The Optical Terrace (La Terrasse Optique in French), which we designed and built in honor of UNESCO's very first International Day of Light (IDL).

\section{ORGANIZATIONAL STRUCTURE}

Based at Université Laval within the Centre d'optique, photonique et laser (COPL), the REPOL's mission is to organize outreach, social and professional development activities for its members, which are mostly graduate students from the research center. In 2014-2015, the REPOL consisted of about 40 members and was composed of eight chapter officers. Since the REPOL was (and still is) a joint SPIE and OSA Student Chapter, the executive positions were:

$\begin{array}{ll}\text { 1. } & \text { Co-President (SPIE) } \\ \text { 2. } & \text { Co-President (OSA) } \\ \text { 3. } & \text { Treasurer } \\ \text { 4. } & \text { Outreach Officer }\end{array}$

1. Co-President (SPIE)

3. Treasurer

4. Outreach Officer

\author{
5. Social and Communcations Officer \\ 6. Conference Officer \\ 7. Industrial Officer \\ 8. Undergraduate Officer
}

While this executive structure proved to be efficient for managing the student chapter over the years, it quickly became evident that it was not adapted for carrying out large-scale projects which required cooperation and specific tasks of its executive members. Therefore, in December 2014 when the student chapter first had the idea of creating an exhibit for the IYL, a new organizational structure was needed. To avoid disturbing the normal course of REPOL's other activities, an organization committee was created in parallel to our student chapter's executive committee, exclusively for the IYL project. As none of the project organizers had experience with similar activities and since the concept of the exhibition could still evolve over time, the best organizational strategy was to create subcommittees of two or more members dedicated to each major aspect of the project. This would help in task and schedule management between all students involved, allowing the committee to create the project on time. The committee structure was as follows: Project Management (2 members), Treasury and Sponsorships (2 members) and Exhibit Hardware Design (4 members).

The hardware design team was mostly responsible for designing and building the exhibit modules to make them robust, easy-to-use, and attractive for the general public. The treasury team was responsible for creating a budget, keeping track of the expenses and finding the necessary funds to complete the project through sponsorships. Finally, the project managers had to coordinate everyone's work and establish a clear roadmap of what needed to be done to turn the concept into a reality and how to do so successfully. This included organizing regular meetings, helping subcommittees either directly or by providing advice, finding potential flaws in the project and making sure that the vision of the project was realistic and respected. One of the managers' critical tasks was to find public places which would welcome the exhibit, and make sure that the format and technical aspects of the project were compatible with these locations.

\section{FINAL DESIGN}

The final design of A Meeting with Light was established in early February 2015. It consisted of four interactive modules built inside transparent boxes, each displaying a different property of light. Each setup was accompanied by a large explanation panel outside the module to complement the showcased experiment. The exhibit was also accompanied by two explanatory banners, one introducing the electromagnetic spectrum and one shedding light 


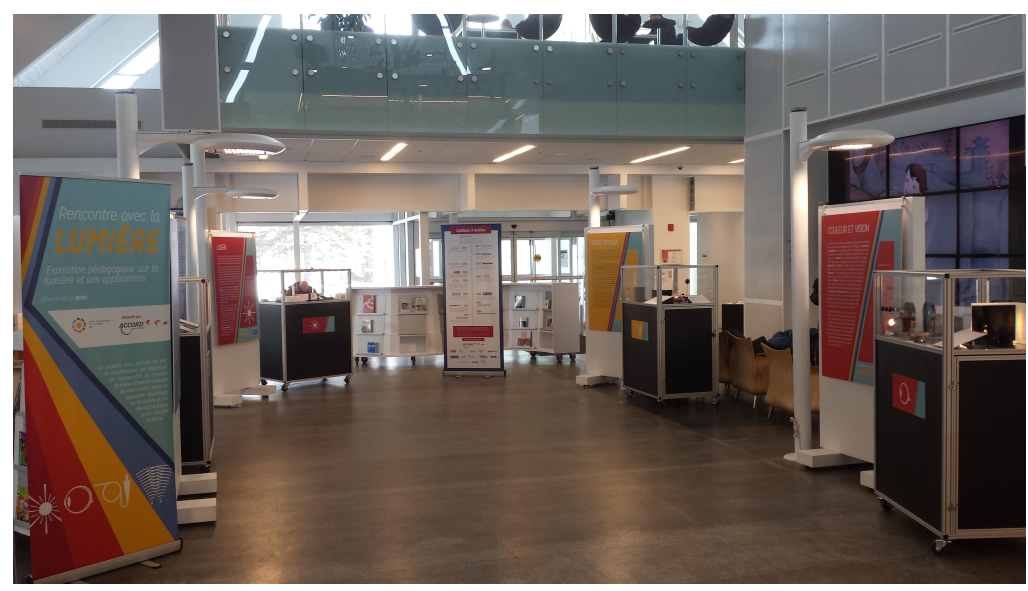

Figure 1: The complete A Meeting with Light exhibit.

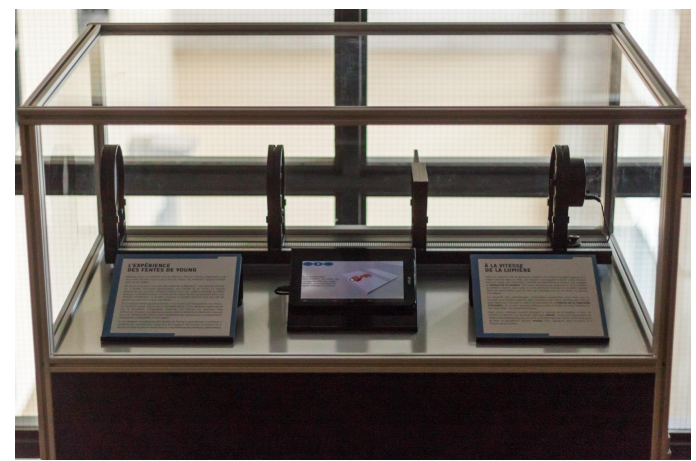

(a) Full view of the Nature of Light display box.

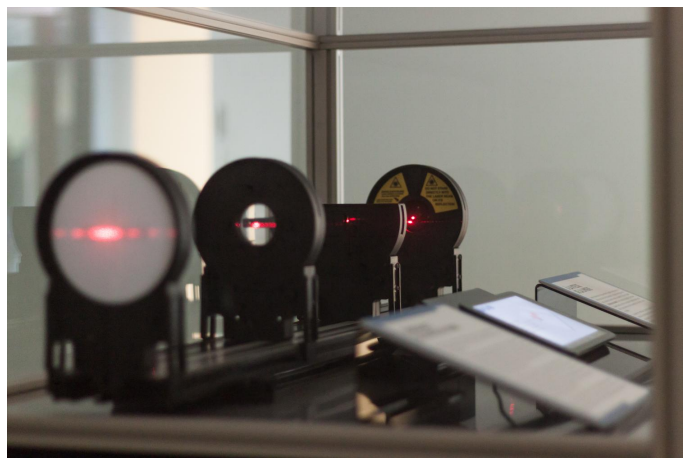

(b) Zoomed-in view of the double slit experiment.

Figure 2: Display box on the wave-like nature of light.

on the large number of $\mathrm{O} \& \mathrm{P}$ companies in Québec City. A welcoming banner briefly explaining the project and its goals was prepared to be placed at the forefront of the exhibit. It is important to note that it was deemed important to hire a graphic designer to prepare the exhibit's banners and posters, as the success of the project would undoubtedly rely on having a professional and attractive look in the eyes of the public.

The different modules are shown in Figures 2 to 5 . The four chosen themes were: The Nature of Light

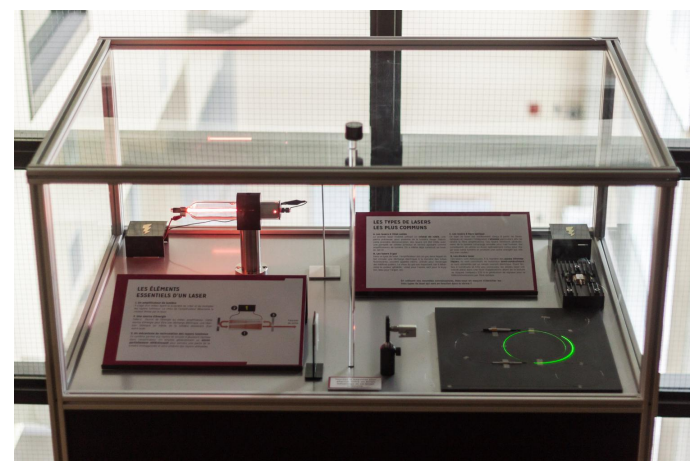

(a) Full view of the Lasers display box.

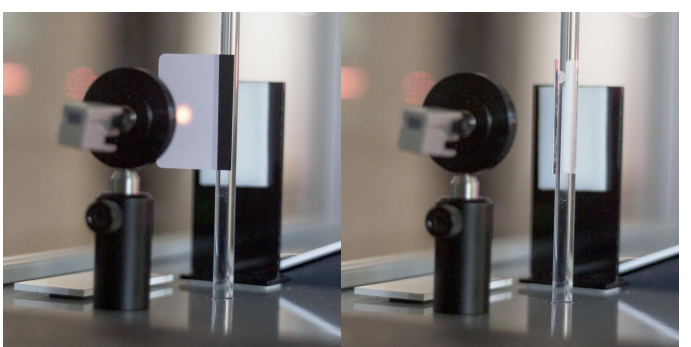

(b) Zoomed-in view of the card that allows the infrared laser to be seen.

Figure 3: Display box on the different types of lasers and a brief description of how they work. 


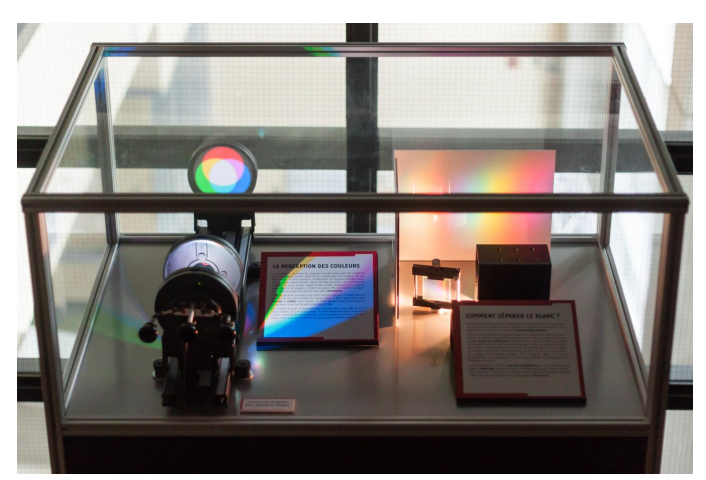

(a) Full view of the Color and Vision display box.

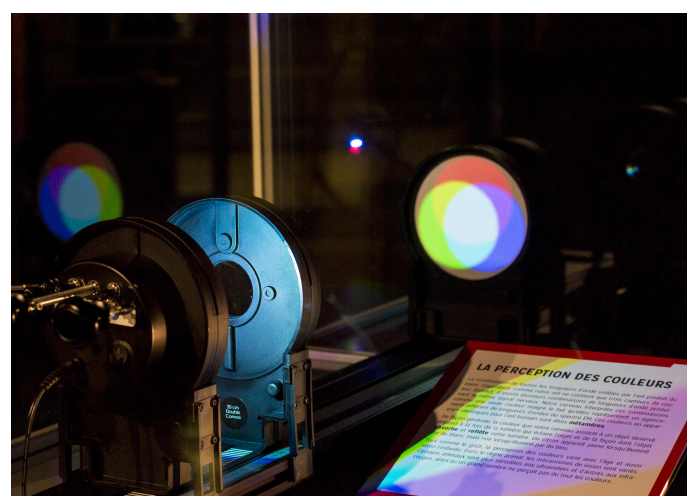

(b) Zoomed-in view of the color experiment.

Figure 4: Display box on the different behaviors of white light.

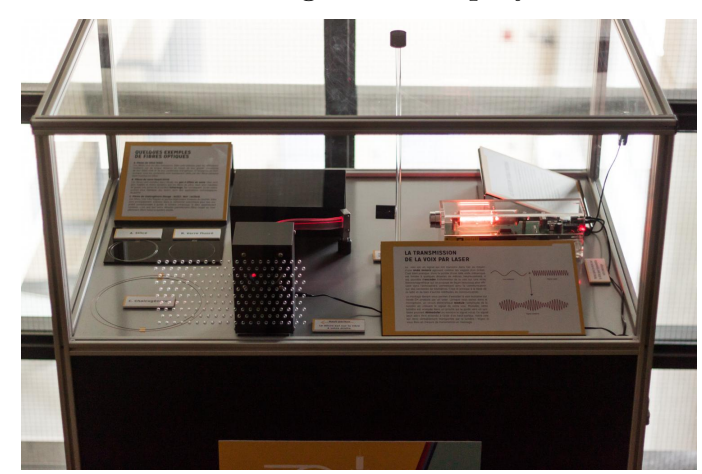

(a) Full view of the Telecommunications display box.

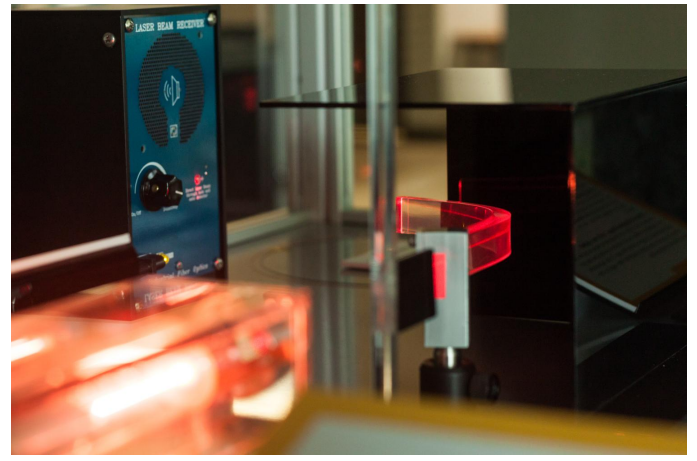

(b) The light from the modulating laser is conducted to a photodetector and linked to a speaker.

Figure 5: Display box on voice modulation and the application of light in telecommunications.

(Figure 2), Lasers (Figure 3), Color and Vision (Figure 4) and Telecommunications (Figure 5). In the first module, a visitor can visualize the wave/particle duality of light through a home-made video continuously playing on a tablet. Behind it, a demonstration of the double-slit experiment is showcased. The second module exhibits the three most common types of laser media (i.e., gas, fibre, semiconductor). A special infrared card allows the viewer to see the invisible laser light produced by a $980 \mathrm{~nm}$ laser diode. To illustrate how the human vision works and the nature of colors, three LEDs (Red-Green-Blue) are directed at a white screen. The user can vary the intensity of each LED individually to modify the resulting color pattern. Finally, the fourth module invites the visitors to speak inside a microphone to experience how information, like a human voice, can be transmitted using light. A laser beam generated from a commercially available voice-modulated laser (Arbor Scientific) is sent through a curved plastic waveguide, imitating the role of an optical fiber, and is collected by a demodulating speaker allowing the person to hear her or his own voice on the other side of the module. A rotating blocker was also placed to interrupt manually the voice transmission by blocking the laser's optical path. All interactive components were designed to be robust and resistant to an intensive use by exhibit visitors.

\section{PROJECT FUNDING}

While each step of the project had its own challenges, funding proved to be the biggest of them all. Our provisional budget is shown in Figure 6 . To find the total amount of $\$ 14,000$ CAD ( $\$ 10,700$ USD), we approached both local industries and non-profit public organizations. Our biggest sponsorship came from the Province of Québec's Ministry of Economy, Innovation and Exportations (MDEIE), which offered to reimburse half of our total expenses. However, since REPOL, our Student Chapter, was officially registered as a student association of Université Laval and not as an independent non-profit organization, the organizing committee could 
Construction hardware

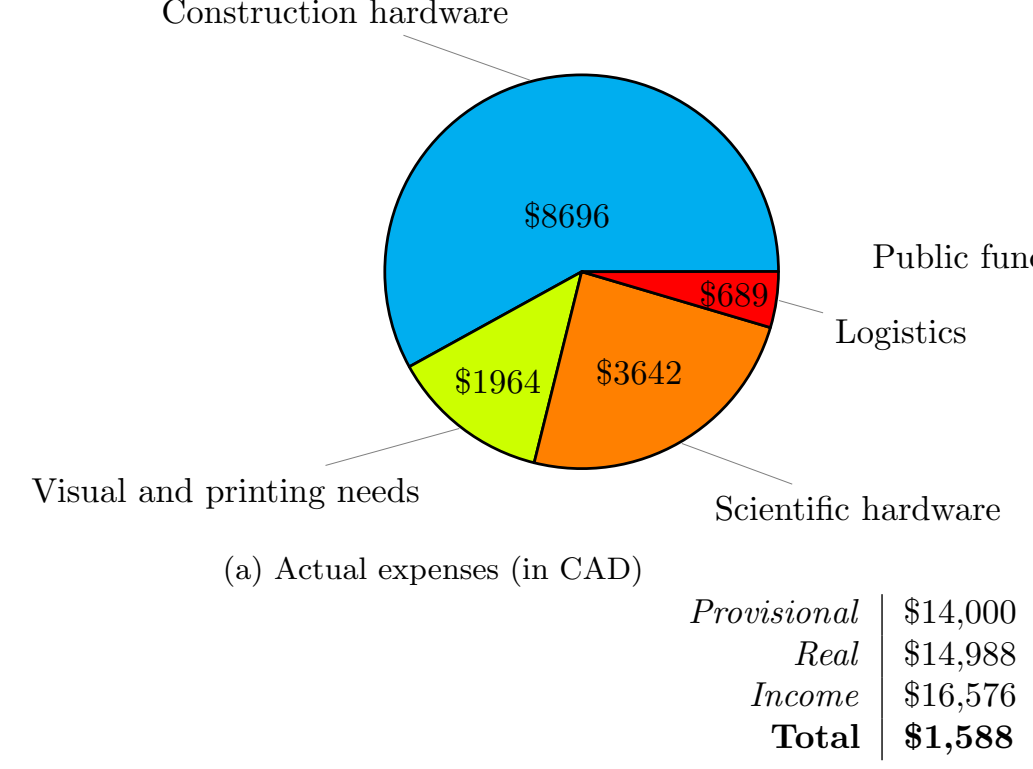

Figure 6: Budget of A Meeting with Light. Inset: Partition of the project's funding sources.

not be in direct control of the funds. The MDEIE had to pass through our university's finance department, which resulted in many administrative and communication difficulties. Unfortunately, this led to delays in constructing the exhibit due to the lack of accessible funds for urgent expenses. On the other hand, thanks to the credibility lent to the project by the governmental MDEIE support, we obtained sponsorships from local companies more easily, which provided the necessary operating funds to cover our primary expenses. An International Year of Light grant of $\$ 500$ USD was attributed to our chapter by SPIE, which contributed to purchasing material. The actual total expenses are shown in Figure 6, which turned out to be of $\$ 14,988$ CAD.

This overshoot of about $7 \%$ was mainly due to an unexpected purchase resulting from an optical component defect. However, savings were made on the logistics side since all moving costs were covered by one of sponsors for the first few months that the exhibit was public. With sponsorships totaling $\$ 16,576$; an amount of $\$ 1,588$ remained to ensure the sustainability of the modules and pay for future moving costs.

\section{IMPACT}

The first showcasing of the exhibit took place on Université Laval's campus from October $19^{\text {th }}$ to November $7^{\text {th }}$, 2015. The motivation behind presenting within the walls of our university first was to test the different modules with a small audience in an easily-accessible environment; this allowed us to collect feedback rapidly and make minor adjustments before moving the exhibit. This first exhibition also allowed the project to be featured in a variety of our university's press. This publicity later helped in inviting partners as well as influential members of the O\&P community and our city's administration to attend the opening ceremony, which took place on January $16^{\text {th }}$ in the city's largest public library (Bibliothèque Gabrielle-Roy), which registered a total of 493 015 visits in 2016. The exhibit, which stayed there until February $16^{\text {th }}$, could be visited freely by people of all ages and backgrounds. During every weekend of the exhibition, members of the organizing committee or student volunteers would be present to animate, discuss and answer questions from the public. During this period, we estimate that about 1000 people visited the exhibit. The exhibit then moved to another one of the city's main public libraries (Bibliothèque Monique Corriveau) for 2 weeks from April $2^{\text {nd }}$ to April $17^{\text {th }}$. The exhibit was also showcased during shorter periods of time for special events, such as the Photonics North 2016 conference and other local outreach events. When the exhibit was not showcased outside of the university, it was either on display in our research center (Centre d'optique, photonique et laser) or simply stored in a dedicated space in the research center. A summary of the exhibition dates and locations is presented in table 1. 


\begin{tabular}{|c|c|c|c|}
\hline Location & Date & Event & People reached \\
\hline Université Laval & Oct. $19^{\text {th }}-$ Nov. $17^{\text {th }} 2015$ & Pre-launch exhibition & 200 \\
\hline $\begin{array}{c}\text { Gabrielle Roy } \\
\text { Public Library }\end{array}$ & Jan. $16^{\text {th }}-$ Feb. $16^{\text {th }} 2016$ & $\begin{array}{c}\text { A Meeting with Light } \\
\text { opening ceremony }\end{array}$ & 1000 \\
\hline $\begin{array}{c}\text { Monique Corriveau } \\
\text { Public Library }\end{array}$ & Apr. $2^{\text {nd }}-$ Apr $17^{\text {th }} 2016$ & $\begin{array}{c}\text { A Meeting with Light } \\
\text { show-casing }\end{array}$ & 300 \\
\hline $\begin{array}{c}\text { Center for Optics, } \\
\text { Photonics and Lasers }\end{array}$ & May $20^{\text {th }}-$ May $22^{\text {nd }} 2016$ & IONS Qubec Conference & 150 \\
\hline Québec Convention Center & May $24^{\text {th }}-$ May 262016 & Photonics North Conference & 400 \\
\hline Québec Exhibition fair & Oct. $19^{\text {th }}-$ Oct. $22^{\text {nd }} 2016$ & Career \& Training Fair & 400 \\
\hline Jeux Photoniques & ${\text { Oct. } 30^{\text {th }} 2016}_{\text {Education \& Outreach Activity }}$ & 140 \\
\hline
\end{tabular}

Table 1: Dates and locations where A Meeting with Light was showcased in 2015-2016. From our estimations, a total of about 2600 people were reached during this period.

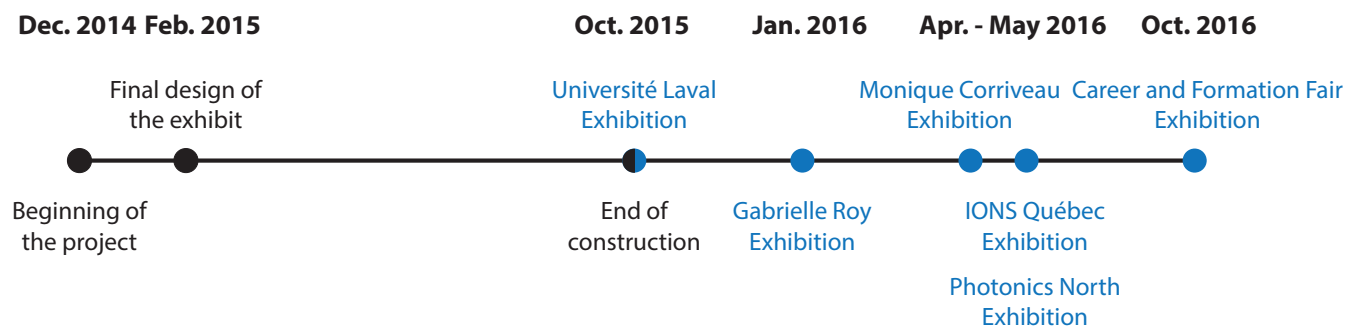

Figure 7: Timeline of the project and dates of the different exhibitions in 2015-2016.

Beyond the educational aspect of the project, A Meeting with Light proved to be an occasion for academia, industry and government to meet and collaborate in an outreach-based context. With the International Year of Light as a catalyst, both the O\&P academic and industrial communities were willing to contribute to our project, which drew attention of our city's administration and our provincial government. This scenario proved to be an ideal opportunity for every stakeholder to forge new bonds within and outside the O\&P network, and this was especially true for our Student Chapter. The relationships built during this project helped the REPOL gain trust from their partners in their student initiatives, which has been key in funding more recent and more ambitious outreach activities, such as The Optical Terrace.

\section{IDL 2018: LA TERRASSE OPTIQUE (THE OPTICAL TERRACE)}

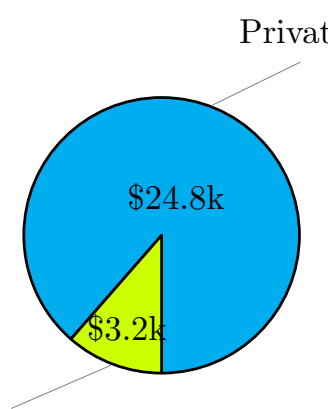

Academic funding

(a) Sponsorship sources (in CAD)

(b) Project budget (in CAD).

\begin{tabular}{c|c} 
Jan/Feb & $\begin{array}{c}\text { Establishing operations } \\
\text { and first design }\end{array}$ \\
\hline Mar/Apr & $\begin{array}{c}\text { Finalizing design, } \\
\text { finding sponsorships, } \\
\text { buying material and } \\
\text { getting permits from city }\end{array}$ \\
\hline May & $\begin{array}{c}\text { Construction in front of } \\
\text { Parliament of Québec and } \\
\text { opening ceremony on IDL }\end{array}$ \\
\hline June & $\begin{array}{c}\text { Moving platform to } \\
\text { the SPOT }\end{array}$ \\
\hline Jul/Aug & Maintenance and promotion
\end{tabular}

(c) Timeline of the project (2018).

Figure 8: Overview of the project La Terrasse Optique. 


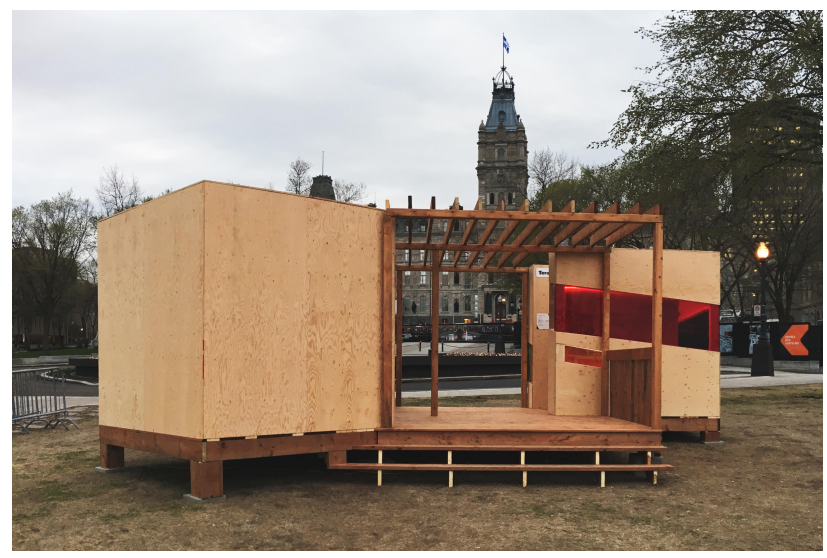

(a) Platform built in front of the Parliament of Québec.

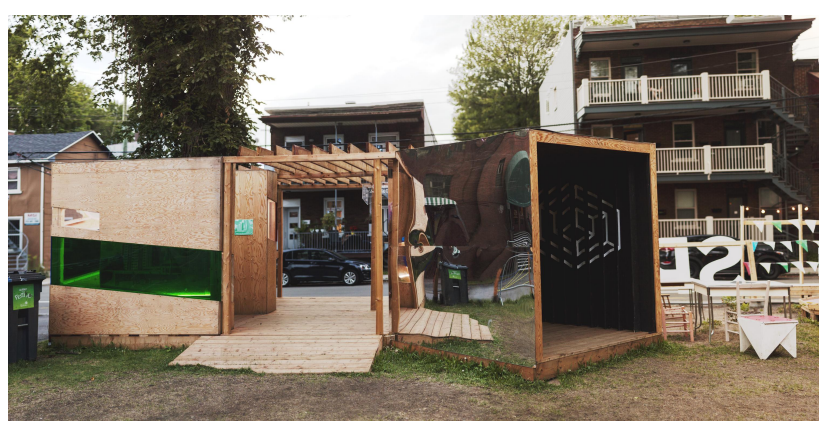

(b) Platform at a family-friendly public space (The SPOT).

Figure 9: Images of the outside of La Terrasse Optique.

The valuable experience gained and the lessons learned by our Student Chapter in making $A$ Meeting with Light were an important foundation in creating our most recent broad-audience outreach project, crafted in honor of UNESCO's very first International Day of Light (IDL). We used this opportunity, in hand with SPIE's IDL Micro Grant (\$3,000 USD), to undertake a large-scale outreach initiative which would be scientific, educational and artistic. The Optical Terrace (La Terrasse Optique in French) is a standalone platform made up of three separate 8-ft wooden cubic structures that people can walk into or through to experience a different light phenomenon. The project was designed and built by our Student Chapter and two of Université Laval's architecture school undergraduates: a total of 12 students contributed to the project's development and construction. In each station can be found a poster giving instructions on what to do, an explanation of the light phenomenon to experience and an application of the given phenomenon in our daily lives. Our goal was to make the concepts as simple as we could so that they could be accessible to as many age groups as possible. We settled on three light phenomena that are integral to our everyday lives but are also accessible through interactive experiences, namely perspective, polarization and spectroscopy.

The Optical Terrace was officially open to the public as of May $16^{\text {th }}$ for the 2018 International Day of light. During the summer of 2018, it was installed in popular public places in Québec City. It was first built in front of Québec's Parliament Building near the touristic Old City, then it was moved for the rest of the summer to a family-friendly public place (The SPOT) at the heart of one of Québec's main neighbourhoods. So far, the platform has been successful in reaching a significant amount of people of all ages. However, as The Optical Terrace is still accessible to the public at the time of publication, estimations on the impact and conclusions on the project's funding and organizational process will be drawn at the end of its first summer of exposition. As an overview, Figure 8 summarizes the main organizational aspects involved in creating The Optical Terrace and Figure 9 shows an exterior view of the completed project at the two locations.

\section{CONCLUSION AND LESSONS LEARNED}

Over the course of the last 10 years, Université Laval's SPIE Student Chapter has gained valuable experience in organizing and hosting outreach activities, which has led to the creation of large-scale, high-impact public outreach projects. Events such as the International 2015 Year of Light or the now-recurring International Day of Light serve as ideal catalysts for mobilizing volunteers and sponsors for putting in place such projects. Looking back on the organizational and technical aspects of putting together A Meeting with Light, we sum up the lessons learned by our Student Chapter by the following words of advice:

- Set up properly all administrative aspects of the project at the very beginning (e.g., how funds are operated and by whom). Outsourcing the administrative tasks (e.g., receiving funds via the university) can be helpful for minimizing the workload on volunteer students, but this may be a less efficient alternative; 
- Remain focused on the established deliverables throughout the project's development (i.e., do not see it as a research project);

- Be sure of your project's final design before building. A design error can have significant time and cost consequences down the line;

- Keep in mind the importance of smart money sponsors can often contribute a lot more resources than funds (e.g., contacts, press, storage, optical components, etc.);

- Do not underestimate the task of simplifying the science; never assume that you simplified it enough. Test your experiments or descriptive texts with friends and family of different ages and backgrounds, and readjust based on their feedback;

- Determine from the get-go whether it will be a one-time project or a sustainable one (e.g., to be used over months or years). It can be an easy task finding dedicated students for building the outreach project, but a difficult one recruiting volunteers for managing and keeping the project alive and relevant in the long run.

\section{REFERENCES}

[1] "Répertoire 2015 de l'industrie optique-photonique du québec," Tech. Rep. V2015-12-14, Réseau Photonique du Québec, Québec, QC (December 2015).

[2] MESI, "S'informer: entreprises de service - optique-photonique (fiche descriptive)." https://www . economie.gouv.qc.ca/objectifs/informer/par-secteur-dactivite/entreprises-de-services/ page/creneaux-dexcellence-20120 (2015 (accessed July $\left.27^{\text {th }}, 2018\right)$ ). 